\title{
Due respect and professional care in death
}

\author{
David Jolley, ${ }^{1}$ Mike Tapley ${ }^{2}$
}

The Psychiatrist (2010), 34, 143-145, doi: 10.1192/pb.bp.109.026260

${ }^{1}$ Pennine Care NHS Foundation Trust and Manchester University; ${ }^{2}$ Willow Wood Hospice, Ashton under Lyne

Correspondence to David Jolley (david.jolley@manchester.ac.uk)
Summary The Royal College of Physicians' Palliative Care Services: Meeting the Needs of Patients and the Department of Health's End of Life Care Strategy are important reports that signify a national and international determination to address the needs of people who are nearing their time of dying, and their families, with positive, wellinformed professionalism. Despite the advances of medicine and improved social conditions, death will eventually supervene. Psychiatrists and other mental health workers encounter death, in anticipation of its coming and in its aftermath. They need to be aware of developments in the field of end-of-life care and contribute to developments which are occurring, as well as learn and assimilate better practices.

Declaration of interest None.

\section{Palliative care in dementia}

The application of palliative care principles in dementia care is encouraged by the National Institute for Health and Clinical Excellence ${ }^{1}$ and in the Department of Health National Dementia Strategy; ${ }^{2}$ it is also the subject of research and service-based publications. There is need for a broader interest in the importance of death in psychiatric practice and the potential of mental health expertise among the dying and their families.

Two important policy documents are discussed below and the main take-home messages illustrated in Box 1.

\section{Palliative Care Services report: ${ }^{3}$ the origins of palliative care}

The Royal College of Physicians' Working Party included Professor Michael King, a psychiatrist, representing the Royal College of General Practitioners, and invited evidence from the Old Age Faculty of the Royal College of Psychiatrists. The report identifies 1967 and the foundation of St Christopher's Hospice as the birth of the modern palliative care movement in the UK, a movement which has been influential worldwide. The authors trace this style of practice to Roman times, continued in the interim in hospices often associated with religious institutions. 'Palliate' comes from the Latin palliare, to cloak or cover. The report presents palliative medicine as characterised by its approach: holistic and valuing quality of life before survival. Grounded in cancer care, its application to non-cancer conditions has received greater emphasis since 2000. Palliation, proactive planned care and attempts to cure are understood to be complementary and not mutually exclusive.

\section{Palliative care in the UK}

Led by voluntary and charitable initiatives, the movement is patchy in its distribution geographically and in its availability according not only to diagnosis (cancer more than any other) but also social class and ethnicity. The 2004 House of Commons Health Committee encouraged better funding and sponsored the End of Life Care Strategy, ${ }^{4}$ urging planners and commissioners to require integrated care across primary, secondary and tertiary healthcare and Social Services.

The Gold Standards Framework (www.goldstandards framework.nhs.uk) and Liverpool Care Pathway (www. mcpcil.org.uk/liverpool-care-pathway) have given reassuring guidance when faced with difficult decisions such as those relating to hydration, pain control, sedation, percutaneous endoscopic gastrostomy feeding and communication.

The Mental Capacity Act 2005 provides a legal incentive to consider the prospect of dying and makes it possible for individuals to comment on their preferred arrangements in anticipation of possible loss of capacity.

There is need for education among doctors and other healthcare professionals on matters such as how to talk with patients and families, to grapple with the issues of rights and how to explain the benefits of opiates.

The trajectory of dying from some (but not all) cancers is fairly predictable and short. Recognition of the beginning of the end is not impossible: features such as becoming bedbound, taking only sips of fluid, not taking oral medication are among the criteria for adopting the Liverpool Care Pathway.

Two alternative trajectories associated with terminal illnesses other than cancer, including dementia, are identified. They have a longer, more erratic time course and the beginning of the end has a less well-defined fingerprint. This means that rigid application of the Liverpool Care Pathway is not appropriate. Iterative reconsideration of an individual's needs for medication, nutrition and other interventions and revision of plans as consequence are required as baselines move over time. Staff 
and family understanding and agreement are integral to success.

Psychological stress and spiritual issues are recognised to be important for everyone approaching death.

Mental health matters are the focus of chapter four of the Royal College of Physicians' report, with depressive symptoms, their identification, interpretation and treatment attracting appropriate discussion. The special needs of people with dementia who are dying are given extensive and sympathetic consideration.

\section{Palliative care - psychological aspects: End of Life Care Strategy ${ }^{4}$}

Psychological aspects of palliative care deserve professional expertise in all modes and in all situations. This means that psychiatrists and other mental health professionals must become competent in the particulars which these situations present. They will require relevant education and training as undergraduates, post-graduates, in continuing professional development, and exposure and experience of end-of-life care. Most who might offer such training are still learning by experience themselves.

The report by the Royal College of Physicians ${ }^{3}$ has much to say about the organisation of palliative care, the staffing of specialist services, audit and research to identify successful and cost-effective interventions, as well as about funding.

It canvasses the replacement of the present variegated pattern of services, which is reliant on the charitable sector, by a centrally funded, equably distributed and controlled service, in keeping with the remainder of the National Health Service (NHS). In these messages, it is a forerunner of the 2008 End of Life Care Strategy. ${ }^{4}$

This document reminds us that half a million people die in England every year. This figure is not changing, but the spectrum of death has progressed towards the very old and away from home to hospital $(60 \%)$ or care home. Despite their valuable contribution to improved understanding and management of a good death, hospices accommodate only $4 \%$ of all deaths and $16 \%$ of cancer deaths.

There is concern that dying is not well managed and the process not widely understood. The general public have become less aware of death. Complaints about care in the final days, particularly for people in general hospitals, are widespread.

The End of Life Care Strategy ${ }^{4}$ addresses death from all causes, not only the predictable deaths which benefit from a palliation. Thus, it encompasses sudden and traumatic deaths, including deaths by suicide and pandemics. It begins with ideas to bring death back into the mainstream of life: open days at funeral parlours and crematoria; educational outreach from hospices in association with schools, colleges and universities; information sessions from solicitors, religious organisations and employers.

Practicalities will require registration of patients known to be at risk of dying soon, so that multi-agency care can be coordinated. There is need for appropriate help to be available on every day and at any hour. Continuity of care and rapid responses are essential - characteristics

\section{Box 1. Summary of main messages}

- Death and dying are being taken seriously

- A palliative approach is appropriate in progressive terminal conditions and is not exclusive to cancer; within mental health, dementia is the condition where palliative care is most often practised

- The Mental Capacity Act provides a legal incentive to plan for death

- Techniques and protocols developed within cancer care can be adopted for flexible use in other conditions

- Spiritual and psychological considerations figure highly for patients and families as the end of life is approached

- The Royal College of Physicians' report ${ }^{3}$ is appreciative of the impact of charity-based hospices, but encourages their assimilation into mainstream NHS services in pursuit of uniform standards and equable service distribution

- The End of Life Care Strategy ${ }^{4}$ addresses death in all its modes and from several perspectives:

- it seeks to bring death and dying out of the shadows, by education and open discussion of practices and issues

- it requires modifications of healthcare systems to address dying more positively and with greater sensitivity to the wishes of patients

- Psychiatrists and mental health services should be aware of these developments and prepare themselves to contribute more effectively to the new interpretation of care for death and the dying

which are difficult to achieve within services distributed across agencies and with personnel constrained by limited working hours.

Management in the event of death requires improvements in the practices of verification and certification as well as providing information and support of the bereaved. The Ministry of Justice will soon publish a charter for the bereaved (www.justice.gov.uk/publications/draft-charterbereaved.htm). Chaplains and other faith leaders play a traditional and important part in general hospitals (there are roughly 450 full-time and 3000 part-time chaplains working in UK hospitals). Additional help may be required in other settings including care homes where 80000 deaths occur annually, many of them with dementia as the main or contributory pathology. Considerable effort is being made to equip care homes to implement the principles of palliative care, improving the experience of death 'in house' and avoiding resorting to terminal admission to general hospitals which have other priorities. Collaborative ventures with hospices are encouraged - St Christopher's dementia project is one example of what can be done.

Special places need special attention: prisons, hostels, special hospitals - perhaps psychiatric units too, although they do not receive mention here. ${ }^{4}$

Workforce development, education and training, audit and research will all require funds and the government is planning to spend £88 million extra in $2009-10$ and $£ 198$ million in $2010-11^{4}$ to make the changes realisable.

Psychiatry, psychiatrists and other mental health workers need to be part of this caring revolution.

The general public is certainly supportive of these initiatives and there is political will at all levels. 
Gordon Brown, ${ }^{5}$ the prime minister, includes Cicely Saunders in his collection of eight personal heroes and leaves us in no doubt that he prefers her vision for medicine ahead of 'cold' biological science.

\section{About the authors}

DavidJolley is Consultant Psychiatrist, Pennine Care NHS Foundation Trust, and Honorary Reader at Manchester University, and MikeTapley works at Willow Wood Hospice, Ashton under Lyne, UK.

\section{References}

1 National Collaborating Centre for Mental Health. Dementia: A NICESCIE Guideline on Supporting People with Dementia and Their Carers in Health and Social Care. British Psychological Society \& Gaskell, 2007.

2 Department of Health. Living Well with Dementia: A National Dementia Strategy. Department of Health, 2009.

3 Royal College of Physicians. Palliative Care Services: Meeting the Needs of Patients. Report of a Working Party. RCP, 2007.

4 Department of Health. End of Life Care Strategy - Promoting High Quality Care for All Adults at the End of Life. Department of Health, 2008.

5 Brown G. Courage. Bloomsbury Publishing, 2007. 